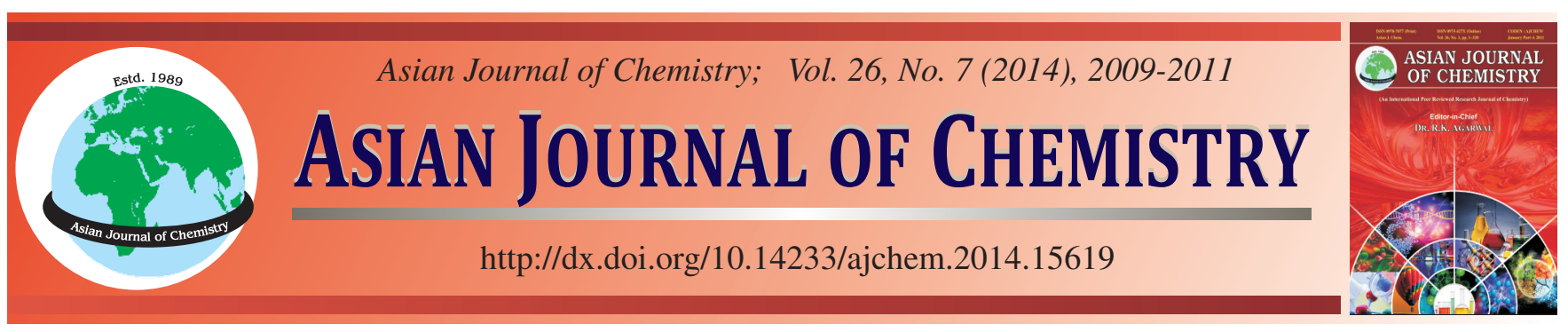

\title{
Synthesis of Nickel Nanoparticles and Characterization by Thermal Decomposition of $\mathrm{Ni}(2,4-\text { di-ClPhAc })_{2}\left(\mathrm{~N}_{2} \mathrm{H}_{4}\right)_{1.5} \cdot \mathrm{H}_{2} \mathrm{O}$
}

\author{
C.R. Sinduja, K. Kalpanadevi and R. Manimekalai*
}

Department of Chemistry, Kongunadu Arts and Science College, Coimbatore-641 029, India

*Corresponding author: Tel: +91 9790374513; E-mail: manimekalair@ymail.com

\begin{abstract}
Nickel nanoparticles have been successfully prepared from nickel carboxylate hydrazinate hydrate as a precursor followed by thermal decomposition. $\mathrm{Ni}(2,4-\mathrm{di}-\mathrm{ClPhAc})_{2}\left(\mathrm{~N}_{2} \mathrm{H}_{4}\right)_{1.5} \cdot \mathrm{H}_{2} \mathrm{O}$ has been prepared and characterized by hydrazine, metal analyses, electronic spectra, infrared spectra and thermal analysis. The precursor shows multistep decomposition to form metallic Ni. The structure and morphology of as prepared Ni nanoparticles were characterized by powder X-ray diffraction, scanning electron microscope, high resolution transmission electron microscope and selected area electron diffraction. The synthesized Ni nanoparticles have average particle size of about $28 \mathrm{~nm}$. This simple and inexpensive synthetic procedure can also be employed to prepare other transition metal nanoparticles.
\end{abstract}

Keywords: Nickel, Metal carboxylatehydrazinate hydrate, Nanoparticle, Thermal decomposition, X-ray analysis.

\section{INTRODUCTION}

Research on nanometer-sized metal/metal oxide nanoparticles has progressed rapidly over the past decade. Nickel nanoparticles are gaining much interest due to their excellent chemical properties like electrical conductivity, melting point, and magnetic properties. They are ferromagnetic in nature ${ }^{1-10}$. The above said interesting characteristics make them potentially important in several fields such as catalysts, fuel cell electrodes, gas sensors, high density recording media, basemetal-electrode multilayer ceramic capacitor (BME-MLCC), battery hybrids, magnetic sensors and memory devices to biomolecular separations ${ }^{11-17}$.

Several physical and chemical methods have been reported for the synthesis of a variety of $\mathrm{Ni}$ nanostructures such as pyrolysis $^{18}$, sputtering ${ }^{19}$, reversed micelles ${ }^{20,21}$, aqueous and nonaqueous chemical reduction ${ }^{22-24}$, sonochemical deposition $^{25}$, polyol method ${ }^{26-31}$, laser-driven thermal methods ${ }^{32}$, liquid-phase synthesis ${ }^{33}$ and an organometallic approach ${ }^{34,35}$ have been applied.

The thermal decomposition is a novel method to produce nickel nanoparticles which is much faster, cleaner and economical as compared to the other conventional methods. In this context, we present a simple and facile synthesis of nickel nanoparticles from the thermal decomposition of an inorganic precursor, nickel 2,4-dichlorophenyl acetate hydrazinate hydrate.

\section{EXPERIMENTAL}

Nickel(II) nitrate hexahydrate, hydrazine hydrate 2,4dichlorophenylacetic acid were obtained from E-Merck and used as received.

The precursor complex was prepared by mixing aqueous solution $(50 \mathrm{~mL})$ containing the nickel(II) nitrate hexahydrate $(0.001 \mathrm{~mol})$ and an aqueous ligand solution $(50 \mathrm{~mL})$ containing 2,4-dichlorophenylacetic acid $(0.003 \mathrm{~mol})$ and hydrazine hydrate $(0.01 \mathrm{~mol})$ in situ with constant stirring. The mixture was kept a side for precipitation. The complex thus precipitated was filtered, washed with alcohol, diethyl-ether and air dried.

The precursor complex thus formed was taken in a clean silica crucible and heated in a low flame gently at first and then strongly during which the complex decomposes completely to give the nickel nanoparticles.

Hydrazine content of the complex was analyzed by titration using $\mathrm{KIO}_{3}$ as titrant ${ }^{36}$. The metal content was estimated by the standard methods given by the $\operatorname{Vogel}^{36}$. The infrared spectrum of the complex was recorded on a Perkin-Elmer model 597 spectrophotometer using $\mathrm{KBr}$ pellets. The solid state electronic absorption spectrum of the complex in Nujol mull was recorded on a Shimadzu UV-visible 240 A spectrophotometer. The simultaneous TG-DTA of the complex in nitrogen atmosphere was carried out using a STA 1500 system. The crystalline phase was characterized by using X-ray diffractometer with $\mathrm{CuK}_{\alpha}$ radiation. The morphology was obtained 
by a Scanning Electron Microscope (SEM). The size was confirmed by a High Resolution Transmission Electron Microscope (HRTEM).

\section{RESULTS AND DISCUSSION}

Formula determination of precursor $\mathrm{Ni}(2,4-\mathrm{di}-\mathrm{Cl}$ $\mathbf{P h A c})_{2}\left(\mathbf{N}_{2} \mathbf{H}_{4}\right)_{1.5} \cdot \mathbf{H}_{2} \mathbf{O}$ : The precursor complex obtained was polycrystalline solid, which was stable in air and insensitive to light. The analytical data of the precursor complex was compatible with the proposed compositions.

The infra-red spectrum of the precursor complex shows a broad band in the region of $3333 \mathrm{~cm}^{-1}$ due to $\mathrm{O}-\mathrm{H}$ stretching of $\mathrm{H}_{2} \mathrm{O}$ molecule ${ }^{37}$. The bands in the region 3200-3149 $\mathrm{cm}^{-1}$ which are assigned to $\mathrm{N}-\mathrm{H}$ stretching frequencies of the hydrazine moieties ${ }^{38}$. The separation of asymmetric and symmetric $\left(\nu_{\text {asymm }}-\nu_{\text {sym }}\right)$ carboxylate stretching of $245 \mathrm{~cm}^{-1}$ indicates the unidentate coordination ${ }^{39}$ of carboxylate ions. The N-N stretching frequency of hydrazine moieties was observed at 973 $\mathrm{cm}^{-1}$ indicating their bridging bidentate nature ${ }^{38}$.

The electronic spectrum of the precursor complex exhibit a band at $28,980 \mathrm{~cm}^{-1}$ which is also attributed to ${ }^{3} \mathrm{~A}_{2 \mathrm{~g}}(\mathrm{~F}) \rightarrow$ ${ }^{3} \mathrm{~T}_{\mathrm{lg}}(\mathrm{P})$ transition, characteristic of octahedral geometry.

The above given data reveals that the proposed formula well suits for the precursor complex $\mathrm{Ni}(2,4-\mathrm{di}$ $\mathrm{ClPhAc})_{2}\left(\mathrm{~N}_{2} \mathrm{H}_{4}\right)_{1.5} \cdot \mathrm{H}_{2} \mathrm{O}$.

Thermal decomposition of precursor to nickel nanoparticles: The precursor complex undergoes three stages of decomposition. The first stage corresponds to dehydration and dehydrazination, which is seen as an exotherm at 229 and $200{ }^{\circ} \mathrm{C}$, confirming the coordination of water molecule. In the second stage, the metal carboxylate decomposes with DTA peak at 495 and $378{ }^{\circ} \mathrm{C}$ to form respective metal carbonate. In the final stage, the metal carbonates decompose exothermically to form the respective metal as the residue. The TG - DTA pattern of $\mathrm{Ni}(2,4 \text { di-Cl PhAc })_{2}\left(\mathrm{~N}_{2} \mathrm{H}_{4}\right)_{1.5} \cdot \mathrm{H}_{2} \mathrm{O}$ is given in Fig. 1.

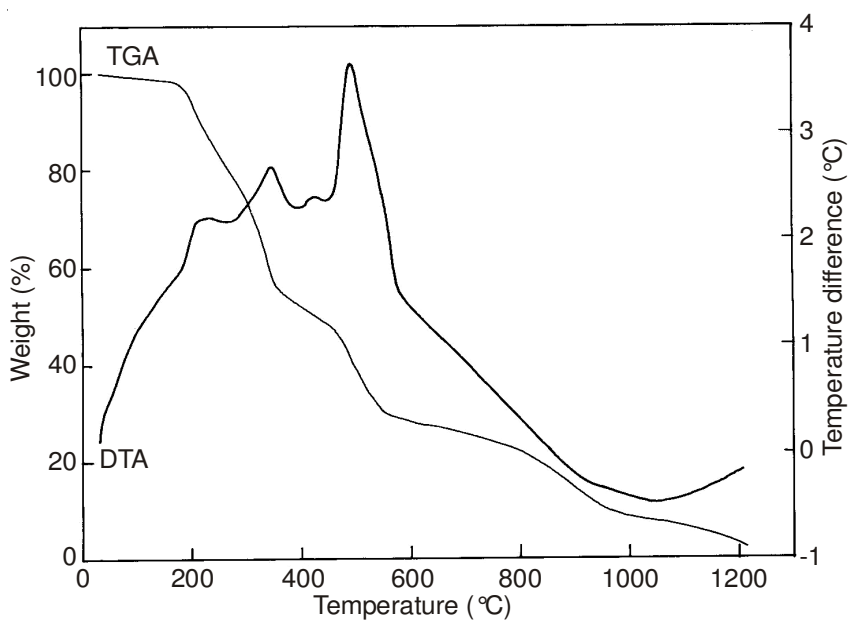

Fig.1. TG-DTA of the precursor

\section{Characterization of Ni nanoparticles}

XRD: The analysis of the crystal structure of the specimen was carried out using XRD. Fig 2. displays the XRD pattern of the obtained Ni nanoparticles. Major diffraction peaks were seen at 44.33, 51.69 and 76.25, which can be assigned to diffraction from (111), (200) and (220) planes, respectively, according to the data base in JCPDS card No: 70-1849. This revealed that the resultant nanoparticles were of pure nickel with a cubic structure. The sharp peaks indicate that the $\mathrm{Ni}$ nanoparticles possess good crystallinity. The average crystallite size was calculated using Scherrer formula from the (111) diffraction peak, which was found to be $28 \mathrm{~nm}$.

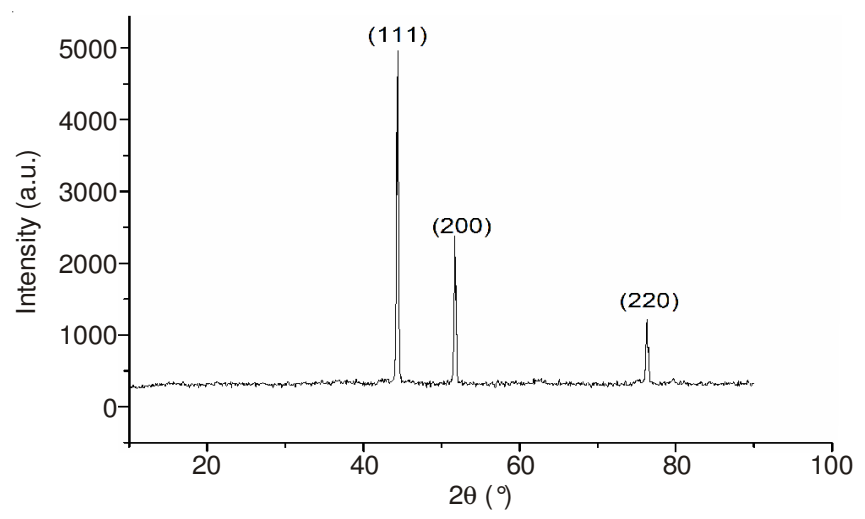

Fig. 2. XRD patterns of the as-synthesized Ni nanoparticles

SEM: The surface morphology of the as-prepared Ni nanoparticles was examined by SEM measurements. Fig. 3 shows the presence of prism-shaped crystal Ni nanoparticles with good separation.
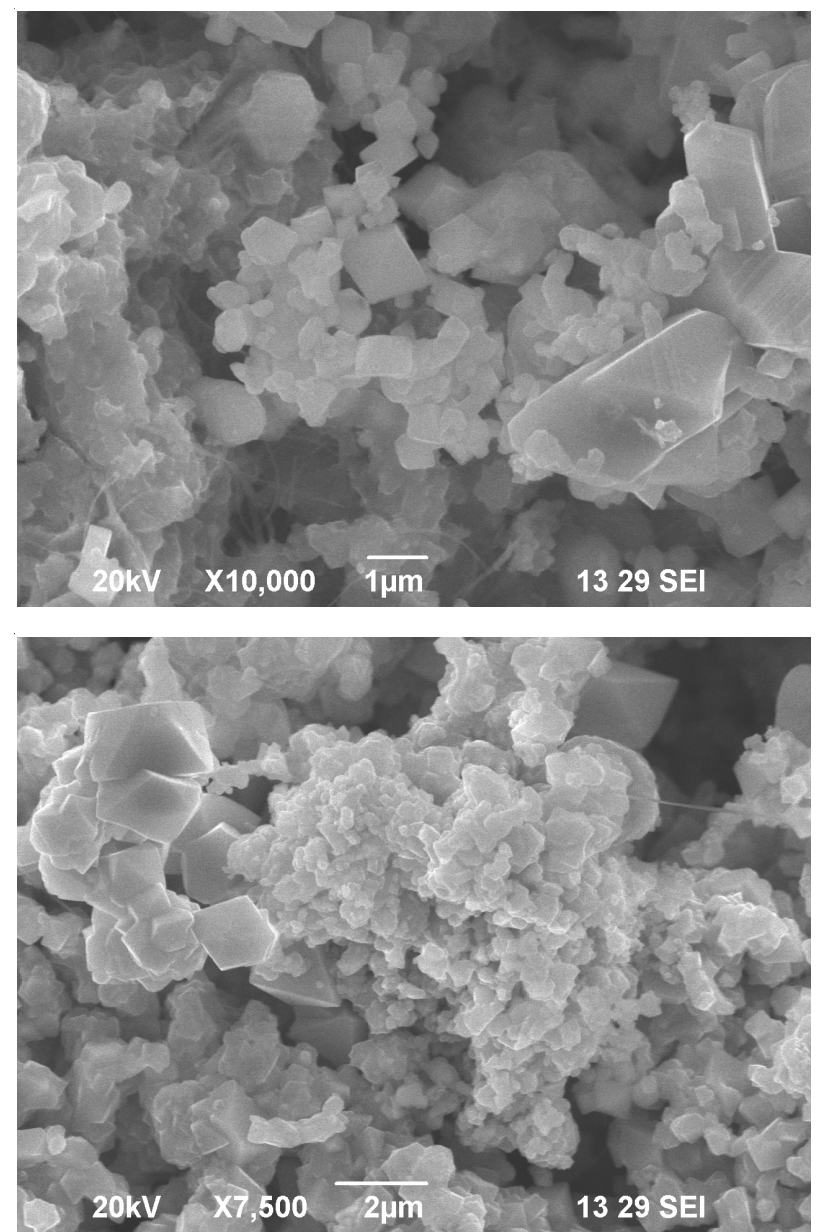

Fig. 3. SEM images of the as-synthesized Ni nanoparticles (two different magnifications) 
HRTEM: The HRTEM images and the corresponding SAED pattern are shown in Fig. 4 and 5. The HRTEM confirms the results obtained from XRD about the phase of Ni nanoparticles. The particles appeared to be agglomerated. The electron diffraction clearly shows the rings belonging to that of nickel. The particle size calculated by HRTEM micrograph was in the range of 27-29 $\mathrm{nm}$.

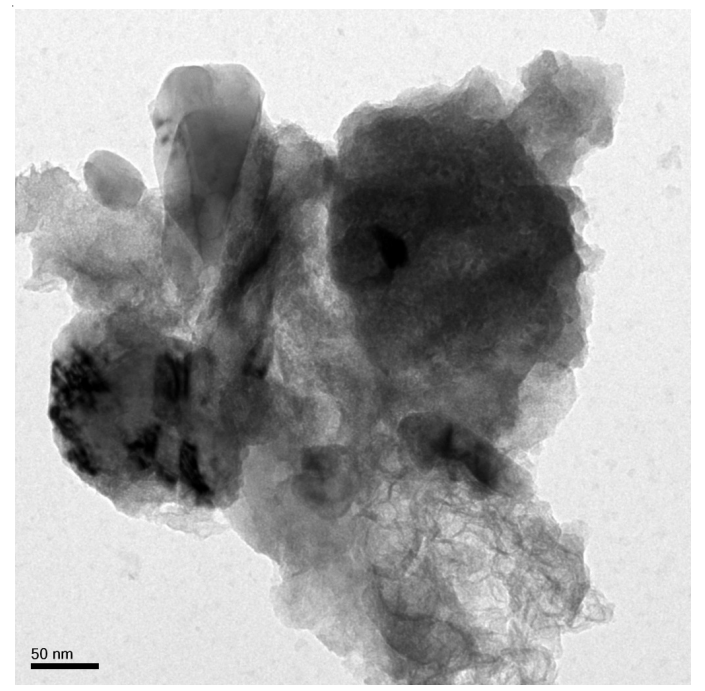

Fig. 4. TEM image of Ni-nanoparticle

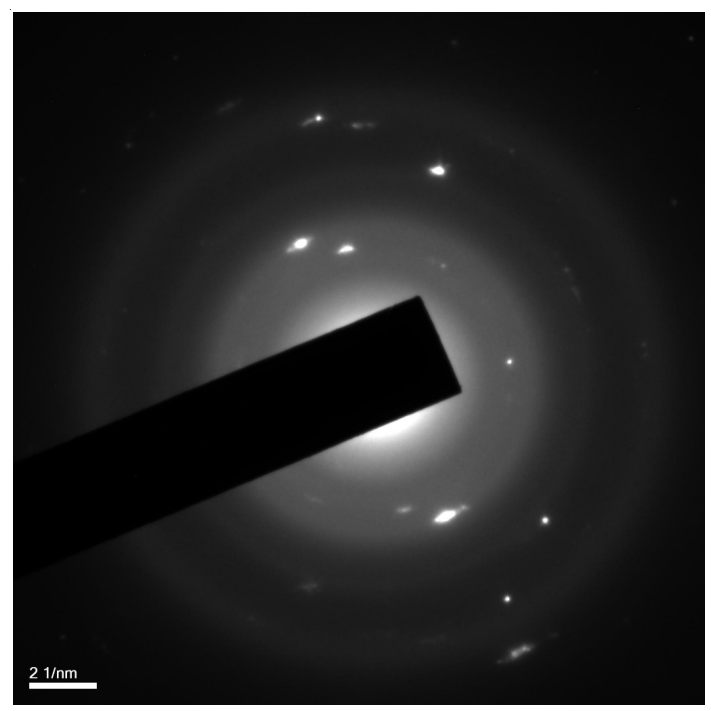

Fig. 5. SAED pattern of the as-synthesized Ni nanoparticles

\section{Conclusion}

In summary, nanosized $\mathrm{Ni}$ particles were synthesized from Ni-2,4 dichlorophenylacetate hydrazinate by thermal decomposition route because of its simplicity and easy scale up. The results obtained from XRD and HRTEM confirm the nanocrystalline nature of the synthesized product. The SEM results depict that a uniform surface morphology and fine nanoparticles are mostly prism shaped with a nanosize range $28 \mathrm{~nm}$. Some agglomeration is also observed. This facile and rapid synthesis may provide a route and understanding for the production of Ni nanoparticles as well as other nanostructures.

\section{REFERENCES}

1. L. Del Bianco, F. Boscherini, A. Fiorini, M. Tamisari, F. Spizzo, M. Antisari and E. Piscopiello, Phys. Rev. B, 77, 094408 (2008).

2. V. Srinivasan and J. Weidner, J. Electrochem. Soc., 144, L210 (1997).

3. P.A. Nelson, J.M. Elliott, G.S. Attard and J.R. Owen, Chem. Mater., 14, 524 (2002).

4. M.R. Thuler, R.L. Benbow and Z. Hurych, Phys. Rev. B, 27, 2082 (1983).

5. L. Del Bianco, F. Boscherini, M. Tamisari, F. Spizzo, M. Vittori Antisari and E. Piscopiello, J. Phys. D., 41, 134008 (2008).

6. A.M. Huntz, M. Andrieux and R. Molins, Mater. Sci. Eng. A, 415, 21 (2006).

7. K. Sakiyama, K. Koga, T. Seto, M. Hirasawa and T. Orii, J. Phys. Chem. $B, \mathbf{1 0 8}, 523$ (2004).

8. A.C. Johnston-Peck, J. Wang and J.B. Tracy, ACS Nano, 3, 1077 (2009).

9. R. Karmhag, T. Tesfamichael, G.A. Niklasson, E. Wackelgard and M. Nygren, J. Phys.D., 34, 400 (2001).

10. V. Singh and V. Srinivas, J. Appl. Phys., 106, 053910 (2009).

11. T. Hinotsu, B. Jeyadevan and C.N. Chinnasamy, J. Appl. Phys., 95, 7477 (2004).

12 G.Y. Guo and H.H. Wang, Chin. J. Phys., 38, 949 (2000).

13. V. Tzitzios, G. Basina, M. Gjoka, V. Alexandrakis, V. Georgakilas, D. Niarchos, N. Boukos and D. Petridis, Nanotechnology, 17, 3750 (2006).

14. W.T. Zheng and C.Q. Sun, Solid State Chem., 34, 1 (2006).

15. V.L. Moruzzi, P.M. Marcus, K. Schwarz and P. Mohn, Phys. Rev. B, 34, 1784 (1986).

16. H. He, R.H. Heist, B.L. McIntyre and T.N. Blanton, Nano Struct. Mater., 8, 879 (1997).

17. M.J. Bonder, E.M. Kirkpatrick, T. Martin, S.-J. Kim, R.D. Rieke and D.L. Leslie-Pelecky, J. Magn. Magn. Mater., 222, 70 (2000).

18. S.L. Che, K. Takada, K. Takashima, O. Sakurai, K. Shinozaki and N. Mizutani, J. Mater. Sci., 34, 1313 (1999).

19. G.B. Thompson, R. Banerjee, X.D. Zhang, P.M. Anderson and H.L. Fraser, Acta Mater., 50, 643 (2002).

20. D.H. Chen and S.H. Wu, Chem. Mater., 12, 1354 (2000).

21. M. Mandal, S. Kundu, T.K. Sau, S.M. Yusuf and T. Pal, Chem. Mater., 15, 3710 (2003).

22. S.H. Wu and D.H. Chen, Chem. Lett., 33, 406 (2004).

23. M. Green and P. O'Brien, Chem. Commun., 1912 (2001).

24. Y. Hou and S.J. Gao, Mater. Chem., 13, 1510 (2003).

25. S. Ramesh, Y. Koltypin, R. Prozorov and A. Gedanken, Chem. Mater., 9, 546 (1997)

26. L.K. Kurihara, G.M. Chow and P.E. Schoen, Nanostruct Mater., 5, 607 (1995).

27. N. Chakroune, G. Viau, C. Ricolleau, F. Fievet-Vincent and F.J. Fievet, Mater. Chem., 13, 312 (2003).

28. G.M. Chow, J. Ding, J. Zhang, K.Y. Lee, D. Surani and S.H. Lawrence, Appl. Phys. Lett., 74, 1889 (1999).

29. H. Yin and G.M. Chow, J. Electrochem. Soc., C68, 149 (2002).

30. P. Toneguzzo, G. Viau, O. Acher, F. Guillet, E. Bruneton, F. FievetVincent and F.J. Fievet, Mater. Sci., 35, 3767 (2000).

31. Y. He, X. Li and M.T. Swihart, Chem. Mater., 17, 1017 (2005).

32. J.W. Park, E.H. Chae, S.H. Kim, J.H. Lee, J.W. Kim, S.M. Yoon and J.Y. Choi, Mater. Chem. Phys., 97, 371 (2006).

33. N. Cordente, M. Respaud, F. Senocq, M.-J. Casanove, C. Amiens and B. Chaudret, Nano Lett., 1, 565 (2001).

34. O. Margeat, D. Ciuculescu, P. Lecante, M. Respaud, C. Amiens and B. Chaudret, Small, 3, 451 (2007).

35. A.I. Vogel, A Textbook of Quantitative Inorganic Analysis, edn 4, Longman, UK (1985).

36. K. Saravanan, S. Govindarajan and D. Chellappa, Synth React. Inorg. Met.-Org. Chem., 34, 353 (2004).

37. A. Braibanti, F. Dallavalle, M.A. Pellinghelli and E. Leporati, Inorg. Chem., 7, 1430 (1968).

38 38. K. Nakamoto, Infrared and Raman Spectra of Inorganic and Coordination Compounds, Wiley, New York (1978).

39. R. Boubekri, Z. Beji, K. Elkabous, F. Herbst, G. Viau, S. Ammar, F. Fiévet, H.J. von Bardeleben and A. Mauger, Chem. Mater., 21, 843 (2009). 